MRS Advances @ 2020 Materials Research Society.This is an Open Access article, distributed under the terms of the Creative Commons Attribution licence (http:// creativecommons.org/licenses/by/4.0/), which permits unrestricted reuse, distribution, and reproduction in any medium, provided the original work is properly cited.

DOI: 10.1557/adv.2020.101

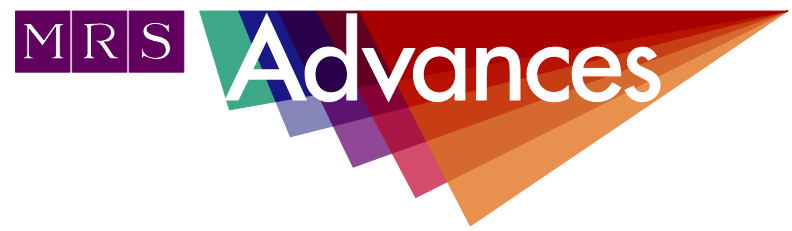

\title{
Integration of the Back-end of the Nuclear Fuel Cycle: An Overview
}

\author{
François Diaz-Maurin ${ }^{1,2}$ and Rodney C. Ewing ${ }^{1,3}$ \\ ${ }^{I}$ Center for International Security and Cooperation, Stanford University, Stanford, CA 94305, USA \\ ${ }^{2}$ Amphos 21 Consulting SL, C/ Venezuela 103, 08019 Barcelona, Spain \\ ${ }^{3}$ Department of Geological Sciences, Stanford University, Stanford, CA 94305, USA
}

\section{ABSTRACT}

Recent efforts have been made toward the integration of the back-end of the nuclear fuel cycle in the United States. The back-end integration seeks to address several management challenges: 1) current storage practices are not optimized for transport and disposal; 2) the impact of interim storage on the disposal strategy needs to be evaluated; and 3) the back-end is affected by-and affects-nuclear fuel cycle and energy policy choices. The back-end integration accounts for the various processes of nuclear waste management-onsite storage, consolidated storage, transport and geological disposal. Ideally, these processes should be fully coupled so that benefits and impacts can be assessed at the level of the full fuel cycle. The paper summarizes the causes and consequences of the absence of integration at the backend of the nuclear fuel cycle in the U.S., critically reviews ongoing integration efforts, and suggests a framework that would support the back-end integration.

\section{INTRODUCTION}

Despite decades of scientific research, engineering analysis, and policy formulation efforts no repository for the geological disposal of highly-radioactive waste is currently operating worldwide. Almost all national efforts to site geologic repositories encountered either public opposition or technical difficulties [1]. In the United States, despite plans for geological disposal, the nuclear waste management (NWM) program, so far, has not gone beyond the surface storage at independent spent fuel storage installations (ISFSIs), all located at or near reactor sites. As of end of 2017, approximately 82,500 metric tons of commercial spent fuel were stored at 79 different locations, including 64 operating reactor sites, spread in 34 states [2]. If no disposal facility becomes available, projections indicate that about 140,000 metric tons of spent 
fuel will be in surface storage by 2050 [3]. To accelerate the removal of spent fuel from reactor sites, proposals have been made in Congress toward the introduction of consolidated interim storage facilities [4]. Interim storage seeks to act as a temporary surface storage solution to the management of spent fuel and high-level waste pending the licensing and construction of the deep geologic disposal capacity required for its permanent disposal.

In this context, efforts have been made toward the integration of the back-end of the nuclear fuel cycle [3,5]. The back-end integration seeks to address several management challenges: 1) current storage practices are not optimized for transport and disposal; 2) the effect of extended long-term dry storage is not well known; 3) the impact of interim storage on the management and disposal strategy must be evaluated; and 4) the back-end is affected by - and affects - nuclear fuel cycle and energy policy choices. The back-end integration accounts for the various processes of the NWM system-onsite storage, consolidated storage, transport and geological disposal (Fig. 1). Ideally, in an integrated analysis framework, these processes should be fully coupled so that benefits and impacts can be assessed at the level of the full fuel cycle. For example, waste treatments that improve waste form durability may improve geological disposal but may not be as attractive further upstream in the back end with respect to handling and conditioning operations during storage. Similarly, repackaging of already packaged spent fuel assemblies into smaller canisters may also improve the potential for geologic disposal, but may have no evident benefit for storage.

The paper summarizes the causes and consequences of the absence of back-end integration in the U.S. and critically reviews past and ongoing integration efforts. We then discuss the challenges posed to such integration and we suggest a framework to address these challenges.

\section{ISSUES IN THE ABSENCE OF INTEGRATION}

The need for integrating the back-end of the nuclear fuel cycle has been discussed mainly in the United States, which has large and diverse inventories of radioactive waste materials requiring storage, transport and disposal [2]. Although the storage of commercial spent nuclear fuel in the U.S. is safe, current practice is optimized for reactor operations, hence not optimized for transportation and disposal [5]. For instance, the use of large dual-purpose canisters (DPCs) allows one to reduce the cost of dry storage and minimize the occupational dose by requiring fewer on-site handling operations. However, some of these containers are not certified by the U.S. Nuclear Regulatory Commission (NRC) for transport. In some other cases, certified DPCs may need to remain stored on-site for several decades to reach the thermal and dose limits required for transportation. Moreover, because of the size and density of DPCs, their direct disposal without repackaging may pose complications, as they are incompatible with all geological disposal concepts except the proposed Yucca Mountain repository in Nevada. Overall, current storage practices imply thermal limits, criticality limits, and canister materials that have not been optimized for disposal in a geologic repository.

In turn, the absence of a clear transport and disposal strategy in the U.S. prevents improving the current storage practice. At the current rate, such practice may create important constraints at the system-level for the management of the nation's waste. Moreover, because current storage practice is considered safe by the NRC, which supervises the operations, the existence of new constraints, such as re-packaging containers before transport, may create an incentive for keeping the spent fuel stored onsite for a much longer period than originally anticipated. Some spent fuel will thus be stored for over 60 years in dry casks that do not have lifetime requirements. Yet, the 
effects of long-term storage in dry casks on waste materials are not well known [6]. The presence of water in geological disposal is known to enhance corrosion and alteration mechanisms affecting the structure of the fuel [7]. Under long-term, dry storage conditions, spent fuel is assumed to be in a dry, closed environment. However, uncertainties exist about the amount of residual water that will remain in the fuel after the drying process when it is transferred to and sealed in the dry casks [6].

\section{CAUSES FOR THE LACK OF INTEGRATION}

There are, at least, two causes for the lack of integration of the back-end of the nuclear fuel cycle. First, the scientific basis for nuclear waste management is not unified. Rather, individual relevant disciplines-materials science, engineering science, geoscience, health science, and social sciences-work in relative isolation from one another [8]. Different disciplines are logically addressing various aspects related to NWM. But, because of the different cultures of the science, engineering and social science communities involved, they tend not to interact. This disconnect between relevant disciplines has prevented the development of technical solutions of NWM in conjunction with societal demands [9]. Whereas the unification of very diverse disciplines does not appear feasible (nor desirable), efforts for their integration should be pursued. A more integrated scientific basis for NWM shall start by recognizing the importance of working at the interfaces between these disciplines. Such integrated approach to knowledge production requires the institutional support of an organization dedicated to NWM, which is not currently the case in the U.S. [10].

Another cause for the lack of integration comes from the large and diverse set of social actors dealing with NWM issues, including utilities, regulators, federal agencies, state institutions, and local communities. Because these players' incentives are not aligned, they cannot drive the back-end of the nuclear fuel cycle to its final solution of permanent geologic disposal [10]. Because each player focuses on its own small part of the larger system, there is no clear and consistent storage, transport, or disposal strategy. This, in turn, generates some confusion which does not build public confidence in proposed technical solutions and contributes to further erode the public trust needed in the institutions currently in charge of NWM.

\section{CURRENT INTEGRATION EFFORTS}

In the United States, current efforts to integrate the spent fuel management system have consisted in developing integration tools and designs. But these efforts have been inconsistent and insufficient.

Integration efforts started in the 1980 s by building an integrated database system that compiled information on waste generation and treatment, characteristics, inventories, and costs [11]. These efforts were later expanded to include projected inventories of spent fuel and analytical capabilities for the calculation of radioactivity and thermal power based on reported or estimated isotopic compositions [12]. However, the official definition of the integrated waste management system (IWMS) did not come until after the Blue Ribbon Commission on "America's Nuclear Future" issued its recommendations in a 160-page report in January 2012 [13]. In its 14-page response to the Blue Ribbon Commission dated of January 2013, the U.S. Department of Energy (DOE) presented its strategy for implementing an IWMS "consisting in a pilot interim storage facility; a larger, full-scale interim storage facility; and a geologic repository in a timeframe that demonstrates the federal commitment to addressing the nuclear waste 
issue" [14]. Thus, priority was given to building new types of facilities in contrast to earlier definitions of systems integration for NWM consisting in developing analytical tools to explore alternative system designs and management scenarios [15].

In recent years, the U.S. DOE has supported the development of various systems analysis tools and designs towards the integration of the waste management system [16]. Initially, legacy systems analysis tools, such as the Transportation Storage Logistics (TSL) and Total System Model (TSM), have been able to analyze multiple management strategies but they lacked fidelity because the modeling was done at an aggregate level of system processes. Currently, the U.S. DOE's Office of Nuclear Energy is supporting the development of modeling and simulation tools for simulating the IWMS, which are significantly more advanced than legacy tools. Additionally, the U.S. DOE also introduced a standard canister design that can integrate transport, aging, and disposal requirements. We provide a brief overview of these integration efforts and discuss their limitations.

\section{UNF-ST\&DARDS integrated database}

The Used Nuclear Fuel-Storage, Transportation \& Disposal Analysis Resource and Data System (UNF-ST\&DARDS) consists of a unified database system that consolidates controls and archives key information from multiple sources, and includes analysis capabilities for storage, transport and disposal. The UNF-ST\&DARDS unified database, being developed and maintained by Oak Ridge National Laboratory, integrates data and information about waste storage and transportation casks and canisters, fuel assembly characteristics, transportation infrastructure, site properties, disposal facility attributes, and costs [16]. The tool can model constraints and steps of an IWMS, provide flexibility to explore yet to be determined system alternatives, and generate output metrics for the evaluation of integrated system performance.

\section{NGSAM simulation software}

The Next Generation Systems Analysis Model (NGSAM) is an agent-based simulation software tool designed for the express purpose of supporting U.S. DOE's IWMS. It is a government "off-the-shelf" software built on open source libraries, with the U.S. DOE owning the source code [17]. The NGSAM, which is currently under development at Argonne National Laboratory in collaboration with other national laboratories, is intended to be used by subject matter experts (SMEs) having distinct levels of expertise allowing them to run alternative waste management strategies and evaluate the performance of each one with respect to various criteria (e.g., cost, schedule). Among other features, the NGSAM will be able to access the UNFST\&DARDS unified database to initialize the model and run integrated scenarios [17]. This feature was not possible with earlier legacy tools that used local databases edited by users and required programmers to run the tools, thus limiting the ability to make integrated management scenarios.

\section{WebTRAGIS and START systems analysis tools}

The U.S. DOE's Office of Environmental Management supported the development of the Web-based Transportation Geographic Interface System (WebTRAGIS). WebTRAGIS includes highway, rail network, and waterway infrastructures which allow intermodal transportation studies. Although not specifically developed for the transportation of radioactive materials, the tool includes features that 
are useful in the context of NWM, such as information on infrastructure proximity (e.g., public schools, hospitals, fire stations) and population density. Using the experience and features from WebTRAGIS, the U.S. DOE's Office of Nuclear Energy has been developing the Stakeholder Tool for Assessing Radioactive Transportation (START) to support the IWMS [18]. START is intended to be used for the evaluation of transportation routing options and emergency preparedness. Using a similar architecture as WebTRAGIS, START consists of a web-based decision-support tool that utilizes geographic information systems (GIS) technology to represent transportation network operations as well as proximate features, such as tribal lands, emergency response capability, schools and environmentally-sensitive areas. These features enable stakeholder groups to participate in the design of transportation routes for SNF, HLW, and other radioactive materials.

\section{$\underline{\text { STAD canister design }}$}

The Standardized Transportation, Aging, and Disposal (STAD) canister was designed by the U.S. Department of Energy's Nuclear Fuels Storage and Transportation Planning Project [19]. The STAD canister can be loaded with either 4 fuel assemblies from a pressurized water reactor (PWR) or 9 from a boiling water reactor (BWR). Its smaller size and weight compared to DPCs makes it much easier to handle during dry storage, transport and disposal. Once loaded, STAD canisters can be either directly inserted in a disposal overpack (yet to be designed) or into a carrier that can hold 4 STAD canisters. The carrier can then be loaded in either a transport cask for off-site transportation or an above ground storage cask for on-site dry storage. During handling operations, the carrier can also be inserted into a transfer cask that provides shielding during fuel loading and transfer into transportation and storage casks.

\section{Limitations of current integration efforts}

Introducing the STAD canister in storage would potentially provide more flexibility to the waste management system, thus facilitating the integration of transport and disposal requirements. However, in the current storage practice, nuclear operators have no incentives for using small canisters [10]. Moreover, even if implemented, the STAD canister would pose operational concern for the already loaded DPCs that would require repackaging. Potentially, the repackaging of DPCs would concern approximately 206,000 BWR and 277,000 PWR fuel assemblies, corresponding to about 11,800 DPCs that would need to be reopened [20], thus losing the benefits of the low radiation exposure obtained from loading large canisters. As of 2016, it was estimated that the use of standard canisters could reduce the total spent fuel management system costs by approximately $2 \%$ to $8 \%$ by continuing to load DPCs [16]. This moderate cost saving however could become insignificant as the introduction of standard canisters in storage is further delayed.

Besides, as we have seen, over the years the U.S. DOE has supported various efforts to develop systems analysis tools that could potentially implement the IWMS. Yet, as proposed, these tools have several limitations that prevent the exploitation of the full potential of integration:

1. The U.S. DOE strategy for NWM and disposal is seen as a linear, stepwise process from storage to disposal [14]. As such, the IWMS mainly consists of building a full-scale interim storage facility and a geological disposal facility in a timeframe that is as short as possible to reduce costs and schedule of the management and disposal strategy implementation. However, it has been 
observed that such "one size fits all" approach is not appropriate for NWM [21].

2. The systems analysis tools supporting the IWMS do not connect the waste management system to its broader societal, technological and environmental context. That is, these tools, such as the NGSAM simulation software, evaluate the performance of the NWM strategy with no considerations of nuclear fuel cycle and energy policy choices, environmental and socio-economic impacts, or technological and natural resources requirements.

More importantly, despite continuous efforts in developing tools, there has been little evidence of their actual use by DOE for building integrated management scenarios. Moreover, access to the systems analysis tools supporting the IWMS is restricted such that the tools are only available for internal or official use. This is the case of the Centralized Used Fuel Resource for Information Exchange (CURIE) website hosted by ORNL and its associated UNF-ST\&DARDS unified database, the WebTRAGIS and START web-based tools, and most probably will be the case also of the NGSAM simulation software which is under development. While prospective users can register and be granted access to WebTRAGIS and START if they meet certain eligibility criteria, the use of the other systems analysis tools is strictly restricted. This restricted access policy results in only the U.S. DOE and national laboratories having the technical capability to conduct integrated analysis. This limitation implies that, currently, the integration of the back-end of the nuclear fuel cycle can only be carried out from the official perspective of the incumbent Administration, making the systems analysis tools and the resulting long-term, integrated management and disposal strategy inherently vulnerable to the political process. This goes against recommendations of opening the issue framing in NWM to more social actors [22-24]. It also ultimately poses a major limitation in the ability to align incentives and explore alternative NWM and disposal strategies.

\section{TOWARDS A FRAMEWORK FOR THE BACK-END INTEGRATION}

Most recently, the purpose of the integration of the back-end of the nuclear fuel cycle has been defined as seeking to [5]: (1) Maximize operational efficiency of nuclear power plants; (2) Minimize handling of SNF and associated occupational radiation doses; (3) Provide for efficient SNF transportation from reactors to repositories; and (4) Support a broad range of permanent geologic disposal options. To achieve such integration dedicated methods of analysis are required. Yet, this corresponds only to a technical definition of what integration means from a system engineering perspective. Rather, integration is a much broader concept that requires more than analytical tools and technology. NWM strategies not only have to be technically feasible, they also must be compatible with a series of societal constraints (regulatory, social, economic, environmental, political) acting as external boundaries to the system.

In systems with policy implications, the societal component of a solutionincluding the process through which the solution was created-matters as much as the technical content of this solution. An integrated approach to NWM systems must first and foremost be able to connect the internal parts (processes) of the system to its broader societal and environmental context. This section provides suggestions for the development of an integrated analysis framework that supports the back-end integration of the nuclear fuel cycle. 


\section{Type and scope of integration}

Although increasingly considered as important for policy, the science of integration is as broad as the science of NWM [8]. Coming from the field of sustainability science, integrative research has been practiced essentially from the perspective of socio-ecological systems [25], with applications to energy supply systems and natural resources management systems [26-28]. In the context of spent fuel management, a system-level integration of the back-end of the nuclear fuel cycle starts by integrating the various storage, transport, and disposal systems (Fig. 1). In this view, a given NWM strategy results from a combination of each one of these systems.

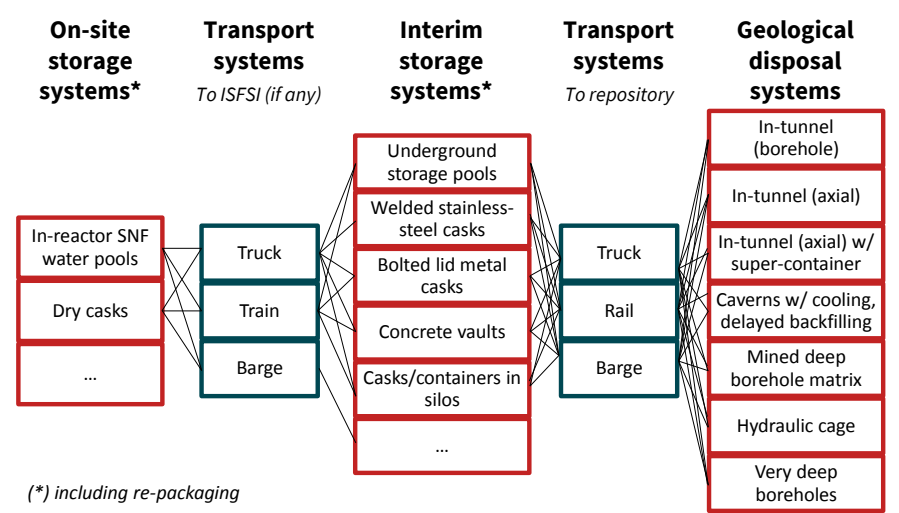

Figure 1: Systems involved in the back-end of the nuclear fuel cycle. Abbreviations: ISFSI, independent spent fuel storage installations; SNF, spent nuclear fuel.

\section{Formalization of the integration}

Formalizing the above system-level integration requires first an analysis of the requirements of each unitary system (process) involved in the back-end of the nuclear fuel cycle. A given process $P_{i}^{j}$ at the back-end of the nuclear fuel cycle (storage systems, transportation systems, and disposal systems) will consist of accepting a given waste input $w_{i}^{j}$, defined through relevant waste attributes (type, volume, composition, radioactivity, and properties) and generating a given waste output $w_{i}^{j+1}$ for which attributes have been modified by the process (Fig. 2). To function, a given process $P_{i}^{j}$ entails a set of constraints $C_{i}^{j}$ on $w_{i}^{j}$ so that:

$$
P_{i}^{j}\left(w_{i}^{j} \mid C_{i}^{j}\right) \rightarrow w_{i}^{j+1}
$$

Examples of constraints internal to each process include, thermal and dose limits for transfer to away-from-reactor storage facilities, waste package type and rate of acceptance by either interim storage facilities or disposal facilities, and the thermal limits and criticality limits for disposal of waste package.

In addition, because a process does work in isolation, it requires various production factors such as technology and resources while it generates safety and environmental impacts (Fig. 2). The back-end integration thus requires an assessment of these external requirements and impacts at the level of each one of the unitary processes 
involved in the waste management system. This is because different management and disposal strategies will result in different types of waste materials and properties having different requirements for each one of the storage, transportation and disposal processes.

A fully integrated back-end of the nuclear fuel cycle must therefore be able to assess the performance of proposed solutions in relation to both internal constraints on waste materials and external constraints on the processes. In turn, this requires being able to perform an integrated analysis across scales.

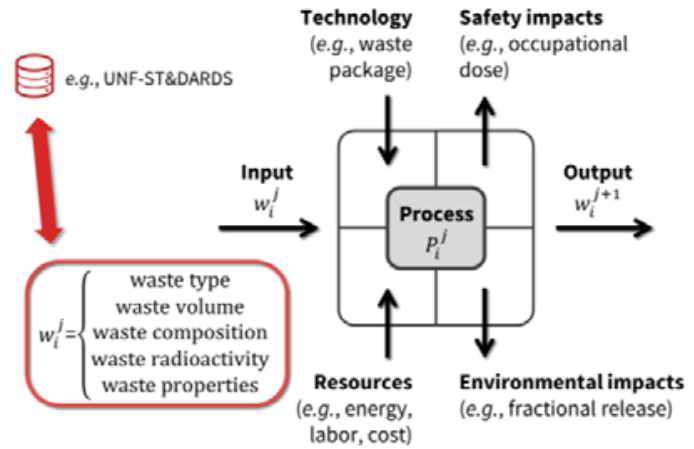

Figure 2: Description of a unitary process for the system-level integration of the back-end of the nuclear fuel cycle.

This formalization allows to have a modular approach to NWM. That is, rather than searching for a unique strategy as the U.S. DOE approach suggests, a more flexible approach to NWM and disposal can consist of a series of solutions that tailor waste properties and conditioning to transport and disposal constraints, and vice versa. In such approach, distinct storage, transport and disposal systems can be considered, even for same waste types (e.g., spent fuel) having different properties (e.g., different burnup rates) (see Fig. 3). Combined, these systems would support the back-end integration by offering a set of integrated strategies which can facilitate progress toward the geological disposal of the overall inventory of radioactive materials. This approach also allows one to evaluate the performance of proposed solutions against their broader context of nuclear fuel cycle choices.

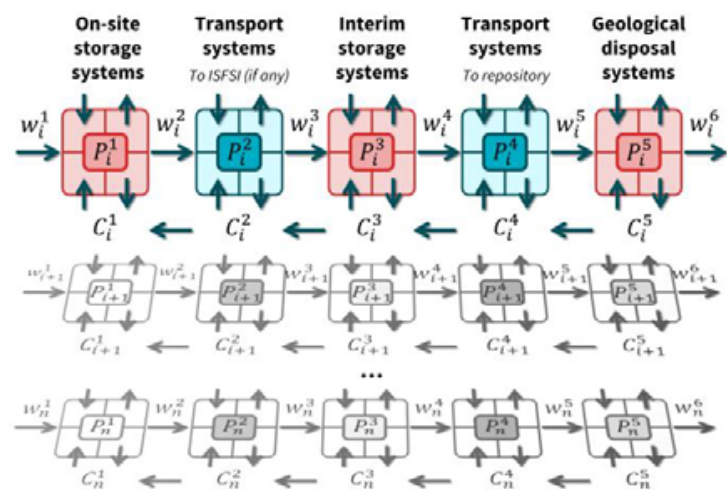

Figure 3: Proposed framework for the waste management system integration. Integration of 5 systems $(j=[1,5])$ and $n$ waste management strategies $(i=[1, n])$. 


\section{$\underline{\text { Decision making from an integration perspective }}$}

Technical solutions cannot be developed in isolation from societal considerations. Even more so, the societal acceptance of a technically rational choice cannot be imposed on stakeholders but, rather, must result from a negotiation through a process of continuous interaction between scientists and society based on trustful relations [29]. Yet, negotiation over societal desirability and technical feasibility of NWM solutions is not possible within the current institutional framework in the U.S.

In the U.S., there has been a systemic lack of public trust in regulatory and other federal agencies in charge of NWM over the past decades [30-32]. Federal agencies have been considered as distant from people's daily lives [33]. This distance fuels the distrust of a public that perceives a lack of commitment from these institutions. Yet, the (political) culture in the U.S. makes institutions not able to negotiate with communities over environmental conflicts and rely, instead, on quantification of objectivity as their conflict resolution strategy [34]. Quantitative information has been increasingly used for the very reason that it can overcome the need for intimate knowledge and interpersonal trust, and thus alleviate distrust in bureaucratic institutions [34]. However, the high reliance on quantification as a mean to objectivity in decision making has been made at the expense of the ability to reach consensus - which is another way to objectivity.

The systemic lack of institutional trust affecting the NWM program in the U.S opens the possibility for a new place given to quantification and a new role for institutions and expertise in the decision-making process. For example, state-level oversight or regulations, as suggested by the Blue Ribbon Commission [13], could be perceived as less distant because local communities have more control on their state institutions.

To address those issues, the approach consists in bringing together relevant scientific and technical information about NWM systems and the perceptions of concerned stakeholders into a quantitative-qualitative analytical framework for the integrated analysis of NWM strategies and policies (see Fig. 1). The resulting process consists of the following steps: i) a pre-analytical discussion where analysts bring together available information in order to build hypothetical NWM scenarios; ii) an informed deliberation where the proposed issue definitions are compared to the perceptions of stakeholders to build updated scenarios; and iii) a policy making and monitoring process where decision can be taken after a consensus is reached. Each one of those steps includes an iterative process that checks the quality of the scientific output generated. 


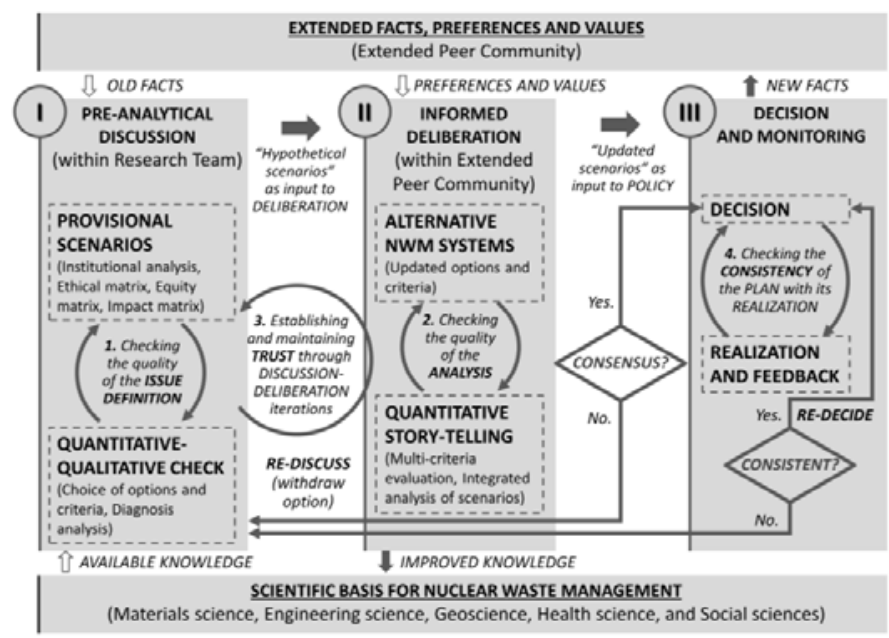

Figure 4: Proposed framework for integration of NWM systems and strategies.

This integrated analytical and decision-making framework would support trust building efforts through the continuous interaction of experts and stakeholders. However, implementing such approach does not appear as possible within the current U.S. institutional framework mainly because it would most likely support a set of small-scale NWM strategies rather than one unique national policy. The proposed framework requires that a new organization be created for the management and disposal of highlyradioactive waste in the U.S. - a recommendation by several independent and international committees of experts and stakeholders $[10,13]$ — as is the case in Finland, Sweden, Switzerland and Canada.

\section{DISCUSSION AND CONCLUSIONS}

Previous integration efforts in NWM have concerned only the U.S. DOE and its national laboratories. However, there is a need for the scientific and engineering community to contribute to the integration of the back-end of the nuclear fuel cycle. This is because scientists and engineers can freely explore waste management and disposal solutions, independent of current official strategies. In return, this approach could greatly benefit official strategies by anticipating possible constraints and, more importantly, finding possible alternative strategies. More broadly, integration tools can also potentially contribute to building public trust, especially if open to the participation of a broader set of social actors. Indeed, enlarging the pool of expertise and perspectives involved in the definition, elaboration, and implementation of NWM strategies has been a central request of the public and social science [21-23].

To avoid further delay in geological repository programs, we need an integrated approach to the back-end that allows interested and affected parties to quickly identify constraints and opportunities for waste management and disposal. To achieve this objective, new analytical tools that can support the back-end integration of the nuclear fuel cycle must be developed. In this paper, we provided an overview of what a framework should include to effectively support the back-end integration. The back-end 
integration must account for the constraints posed by the transportation of spent fuel to interim storage facilities and/or to geological disposal facilities. In addition, the back-end integration should be considered early in the nuclear fuel cycle choices. Certain types of waste materials, waste forms, and waste packages will have different requirements for the storage, transportation and disposal. Similar frameworks have been developed for the multi-scale integrated analysis of energy supply systems, natural resources management systems, and non-hazardous waste management systems [26-28,35].

Although this paper has focused on the U.S. situation, the proposed framework can support integration efforts in any country having to deal with NWM and disposal issues. Of course, in countries with only one type of waste material requiring geological disposal (e.g., commercial SNF), one waste storage system (e.g., fuel assemblies in water pools), one geological setting to host a repository (e.g., crystalline rock in Sweden and Finland), and/or relatively short transportation distances (e.g., Switzerland or Belgium), the need for an integration of the back-end of the nuclear fuel cycle is not so great. For other countries, however, having a large and diverse set of waste types and associated management systems, such as in France, Russia, the United Kingdom, and the United States, the back-end integration and analysis of the fuel cycle is an essential first step in developing a viable strategy for waste management and disposal.

The implementation of the proposed framework in the U.S. would require that a new NWM organization take over the responsibility of managing radioactive waste, independently from the changing political context. The establishment of a new institution shall start by carefully defining the terms of its responsibilities, mandate, degree of freedom, accountability, internal functioning and staffing. All these attributes shall be defined considering their potential impacts - positive or negative - on public trust. Such a discussion may require the definition of NWM strategies that accommodate their different legal and regulatory frameworks, as well as their different technical processes. The integrated approach briefly presented here intends to support this institutional reform. Yet, there is a consensus among those proposing to reform the U.S. NWM program that its implementation would take a significant amount of commitment, particularly of financial and human resources, and that benefits will pay off only decades from now [13,29,36,37]. Nevertheless, few options exist, if any, other than engaging such institutional reform that focuses on building and maintaining public trust to develop and implement long-term NWM strategies.

\section{ACKNOWLEDGMENTS}

The project leading to this publication has received funding from the European Union's Horizon 2020 research and innovation program under the Marie SklodowskaCurie grant agreement No 739850, as well as from the MacArthur Foundation under the Nuclear Security Fellowship program of the Center for International Security and Cooperation (CISAC) at Stanford University. The authors thank the two anonymous reviewers for their useful comments and suggestions on an earlier version of this paper.

\section{REFERENCES}

1. U.S. NWTRB, Survey of National Programs for Managing High-Level Radioactive Waste and Spent Nuclear Fuel: A Report to Congress and the Secretary of Energy (United States Nuclear Waste Technical Review Board, Arlington, VA, 2009).

2. J. Carter, Spent Nuclear Fuel and High-Level Radioactive Waste Inventory Report (Savannah River Site (SRS), Aiken, South Carolina, USA, 2018). 
3. R.P. Rechard, L.L. Price, and E.A. Kalinina, Integrating Management of Spent Nuclear Fuel from Generation to Disposal (Sandia National Laboratories, Albuquerque, NM, 2015), p. 45.

4. U.S. Senate Committee on Environment and Public Works (2019).

5. E.J. Bonano, E.A. Kalinina, and P.N. Swift, MRS Advances 3, 991 (2018).

6. J. Bruno, L. Duro, and F. Diaz-Maurin, in Advances in Nuclear Fuel Chemistry 1st Edition edited byM. Piro (Woodhead Publishing, 2020), p. 450.

7. R.C. Ewing and W.J. Weber, in Fundamentals of Materials for Energy and Environmental Sustainability edited byD.S. Ginley and D. Cahen (Cambridge University Press, 2011), pp. $178-193$.

8. F. Diaz-Maurin, H.C. Sun, J. Yu, and R.C. Ewing, MRS Advances 4, 959 (2019).

9. F. Diaz-Maurin and R.C. Ewing, Sustainability 10, 4390 (2018).

10. Reset Steering Committee, Reset of America's Nuclear Waste Management Strategy and Policy (Stanford University, Stanford, CA, 2018).

11. C.A. Johnson, Radioactive Waste Management: A Bibliography for the Integrated Data Base Program (Oak Ridge National Lab., TN (USA), 1981).

12. U.S. Department of Energy, Integrated Data Base Report-1996: U.S. Spent Nuclear Fuel and Radioactive Waste Inventories, Projections, and Characteristics (Washington, D.C., 1997), p. 263

13. Blue Ribbon Commission on America's Nuclear Future, Report to the Secretary of Energy (U.S. Department of Energy, Washington, DC, 2012).

14. U.S. Department of Energy, Strategy for the Management and Disposal of Used Nuclear Fuel and High-Level Radioactive Waste (U.S. Department of Energy, Washington, D.C., 2013), p. 14.

15. W.J. Danker and J.R. Williams, in High Level Radioactive Waste Management (American Nuclear Society, Las Vegas, NV (USA), 1990).

16. J. Jarrell, in (U.S. Nuclear Waste Technical Review Board, Washington, D.C., 2016), p. 29

17. R. Joseph, B. Craig, R.M. Cumberland, C. Trail, J. St. Aubin, C. Olson, L. Vander Wal, E. Vanderzee, J. Jarrell, and E. Kalinina, in (Oak Ridge National Lab. (ORNL), Oak Ridge, TN (United States), Phoenix, Arizona, USA, 2019).

18. M. Abkowitz and E. Bickford, in (American Nuclear Society, Charleston, SC, USA, 2015).

19. U.S. Department of Energy's Nuclear Fuels Storage and Transportation Planning Project, Small Standardized Transportation, Aging, and Disposal (STAD) Canister System For Spent Nuclear Fuel Management (U.S. Department of Energy, Washington, DC, 2015), p. 2 .

20. R. Howard, in (U.S. Nuclear Waste Technical Review Board, Washington, D.C., 2013), p. 20.

21. U.S. Department of Energy, Designing a Consent-Based Siting Process: Summary of Public Input (Washington, D.C., 2016), p. 98.

22. J. Dewoghélaëre, G. Hériard-Dubreuil, and Y. Marignac, Civil Society Views on the Content and Governance of a Joint Research Programme (JOPRAD - Towards a Joint Programming on Radioactive Waste Disposal. (EU project H2020-Euratom-653951), Paris, France, 2017), p. 11.

23. A. Brunnengräber and M.R. Di Nucci, editors, Conflicts, Participation and Acceptability in Nuclear Waste Governance: An International Comparison (Springer VS, Wiesbaden, 2019).

24. B.D. Solomon, M. Andrén, and U. Strandberg, Risk, Hazards \& Crisis in Public Policy 1, 13 (2010).

25. A. Kliskey, L. Alessa, S. Wandersee, P. Williams, J. Trammell, J. Powell, J. Grunblatt, and M. Wipfli, Sustain Sci 12, 293 (2017).

26. K. Mayumi and M. Giampietro, Ecological Indicators 47, 50 (2014).

27. M. Giampietro, R.J. Aspinall, J. Ramos-Martin, and S.G.F. Bukkens, editors, Resource Accounting for Sustainability Assessment: The Nexus between Energy, Food, Water and Land Use (Routledge, New York, NY, USA, 2014)

28. F. Diaz-Maurin and M. Giampietro, Energy 49, 162 (2013).

29. T.R. La Porte and D.S. Metlay, Public Administration Review 56, 341 (1996).

30. S.E. Robinson, J.W. Stoutenborough, and A. Vedlitz, Understanding Trust in Government: Environmental Sustainability, Fracking, and Public Opinion in American Politics (Routledge, New York, NY, 2017).

31. M. Greenberg, Nuclear Waste Management, Nuclear Power, and Energy Choices: Public Preferences, Perceptions, and Trust (Springer Science \& Business Media, 2012).

32. P. Slovic, J.H. Flynn, and M. Layman, Science 254, 1603 (1991).

33. F. Diaz-Maurin, Bulletin of the Atomic Scientists 74, 335 (2018).

34. T.M. Porter, Trust in Numbers: The Pursuit of Objectivity in Science and Public Life (Princeton University Press, Princeton, NJ, USA, 1995).

35. R. Chifari, S. Lo Piano, S.G.F. Bukkens, and M. Giampietro, Ecological Indicators (2016).

36. L.E. Davis, D. Knopman, M.D. Greenberg, L.E. Miller, and A. Doll, Choosing a New Organization for Management and Disposition of Commercial and Defense High-Level Radioactive Materials (RAND Corporation, Santa Monica, CA, 2012).

37. J. Flynn, R. Kasperson, H. Kunreuther, and P. Slovic, Issues in Science and Technology 8, 42 (1992). 